\title{
Kleptomania, impossible to resist: regarding a clinical case of Obsessive Compulsive Disorder that ends up turning on Kleptomania
}

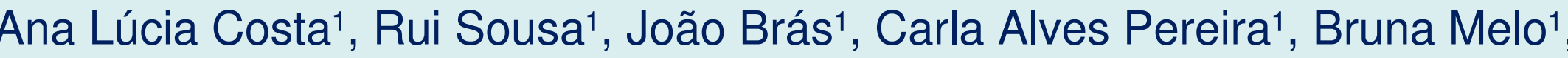

Alberto Marques ${ }^{1}$, David Teixeira1 ${ }^{1}$, Ana Isabel Oliveira ${ }^{1}$, Jorge Humberto Silva ${ }^{1}$ 1. Department of Psychiatry and Mental Health, Centro Hospitalar Tondela-Viseu, EPE., Viseu, Portugal.

\section{BACKGROUND}

AND AIMS

Kleptomania is an impulse control disorder characterized by the inability to resist the impulse to steal objects that aren't needed, and often times have no significant value. A review of research suggests that kleptomania may be a common disorder among women, and that it may frequently be associated with other forms of psychopathology, such as mood and anxiety. Kleptomania is classified in the DSM-5 in the category of Disruptive, Impulse-Control and Conduct disorders.

\section{OBJECTIVES}

To present a clinical case of Kleptomania that develops after a diagnosis of OCD (Obsessive-Compulsive Disorder).

\section{MATERIAL AND} METHODS

Case report and a literature search was conducted using the search engine Pubmed $\AA^{\circledR}$ and the keywords Kleptomania and impulse control disorders.
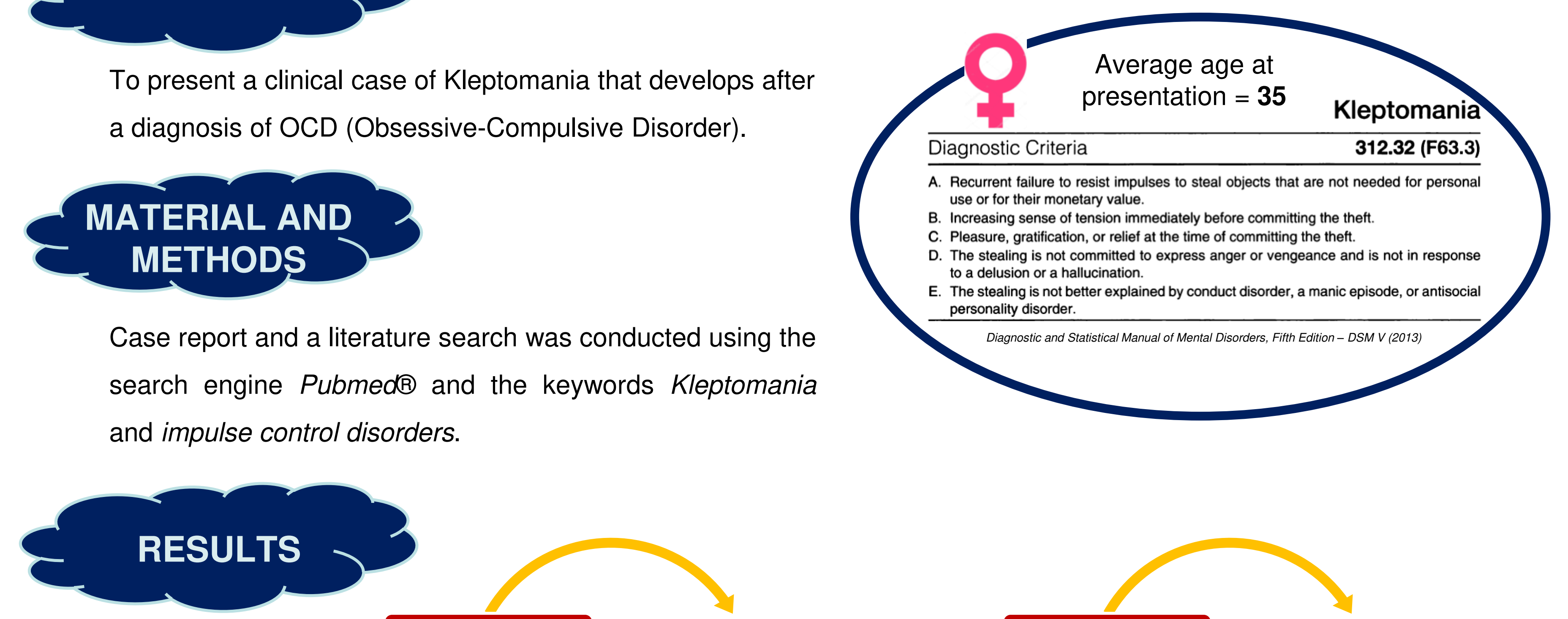

?

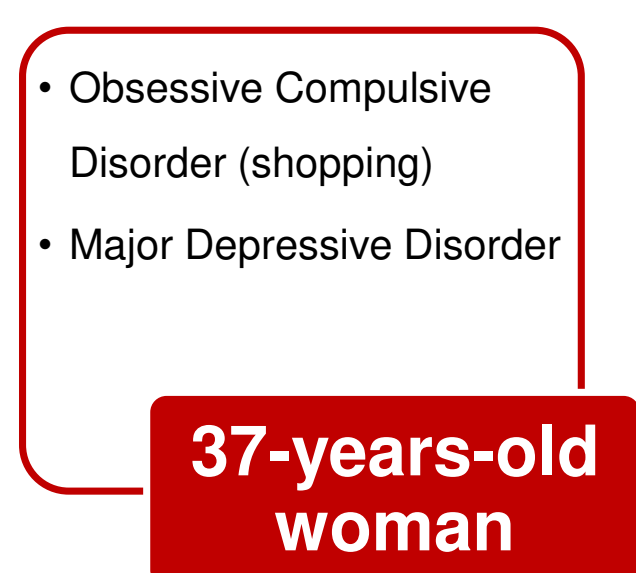
woman

\section{Background}

stressful childhood (attempted sexual abuse by stepfather) - familial conflicts - lack of self-esteem

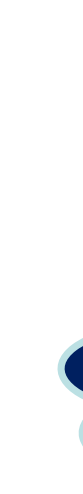

\section{CONCLUSION}

Diagnosed with Kleptomania
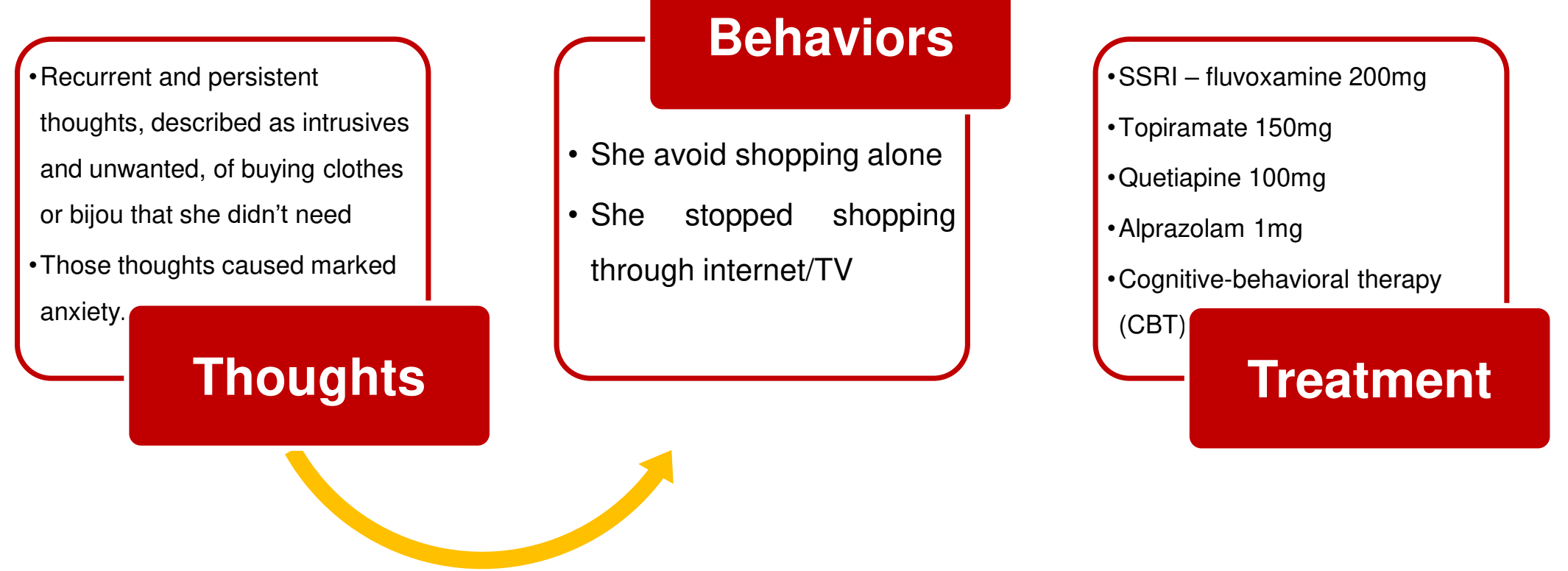

Kleptomania often goes unrecognized in clinical practice because of the reluctance to seek treatment and its associated social stigma. Those with kleptomania only seek treatment when they already have legal, social, family or occupational problems or when there is a comorbidity with mood and anxiety disorders, which is quite common. Fluvoxamine, a SSRI, was chosen for treatment because of these comorbidities in association with CBT. Evidence suggests that there may be subtypes of kleptomania that are more like $O C D$, whereas others have more similarities to addictive or mood disorders. 